\title{
Cidades saudáveis: $o$ acesso equitativo a parques urbanos como promoção da saúde
}

\section{Healthy cities: equitable access to urban parks as health promotion}

Article Info:

Article history: Received 2021-03-29 / Accepted 2021-03-29 / Available online 2021-03-30 doi: 10.18540/jcecvl7iss1pp12020-01-14e

\begin{abstract}
Ana Raquel Santos de Meneses
ORCID: https://orcid.org/0000-0003-3784-9027

Mestra e Doutoranda do Programa de Pós-Graduação em Desenvolvimento Urbano - PPGDU (MDU) / Universidade Federal de Pernambuco - UFPE, Brasil

E-mail: raquel.meneses@gmail.com

Marcela Marçal Maciel Monteiro

ORCID: https://orcid.org/0000-0001-6923-9376

Mestra em Engenharia Civil, professora do Instituto de Engenharia do Araguaia - IEA/ Universidade Federal do Sul e Sudeste do Pará - UNIFESSPA, Brasil E-mail: marcela.monteiro@unifesspa.edu.br

Wirenilza do Nascimento Lima

ORCID: https://orcid.org/0000-0002-8903-2839 Graduanda em Arquitetura e Urbanismo da Universidade Federal do Rio Grande do Norte -

UFRN, Brasil

E-mail: wirenilza@gmail.com

Ricardo Victor Rodrigues Barbosa

ORCID: https://orcid.org/0000-0003-4971-6037

Doutor em Ciências da Engenharia Ambiental, Professor do Programa de Pós-Graduação em Arquitetura e Urbanismo - PPGAU / Universidade Federal de Alagoas - UFAL, Brasil

E-mail: rvictor@,fau.ufal.br
\end{abstract}

\section{Resumo}

$\mathrm{O}$ artigo analisou parques urbanos em duas capitais brasileiras - Belém-PA e Recife-PE - a partir do padrão de distribuição e atendimento à população por meio da identificação, dimensões e estimativa de suas áreas de alcance. Quanto à localização, observou-se que a maioria dos parques urbanos, nas duas cidades, se concentra em áreas centrais, distantes de bairros periféricos com menor padrão de renda. Quanto ao percentual de área de atendimento, verificou-se que a quantidade de pontos de acesso aos parques teve maior influência do que a área total coberta por parques na cidade. Por fim, o estudo aponta para a importância de um planejamento eficiente para acesso da população, de forma equitativa, aos benefícios ecossistêmicos proporcionados por esses espaços com vistas à melhoria da qualidade de vida nas cidades.

Palavras chaves: Áreas verdes urbanas. Planejamento urbano. Infraestrutura verde.

\section{Abstract}

The research analyzed urban parks in two Brazilian capitals - Belém-PA and Recife-PE - based on the pattern of distribution and service to the population through the identification, dimensions and estimation of their reach areas. Regarding location, it was observed that most of the urban parks, in both cities, are concentrated in central areas far from peripheral neighborhoods with low-income population. As for the percentage of service area, it was found that the number of access points to the parks had a greater influence than the total area covered by parks in the city. The study points to the importance of an efficient planning for the population's access, in an equitable way, to the ecosystem benefits provided by these spaces aiming at improving the quality of life in cities.

Keywords: Urban green areas. Urban planning. Green infrastructure. 


\section{Introdução}

A contínua expansão espacial e populacional nas cidades, especialmente as localizadas em países em desenvolvimento, cujo crescimento urbano dá-se de forma intensa e desordenada, tem fomentado discussões sobre as questões ambientais no ambiente urbano, com destaque àquelas relativas ao bem-estar e infraestrutura adequada a todos os habitantes.

Entre os efeitos adversos da expansão urbana, tem-se observado a redução progressiva da quantidade de áreas verdes com impacto direto na interação entre espaço público e população, além da formação de ambientes termicamente desconfortáveis, de modo a favorecer à insustentabilidade no meio urbano (Almeida et al., 2017).

Nesse sentido, as áreas verdes torna-se pauta premente no processo de "pensar" a cidade. Os parques urbanos se destacam por garantir a permanência das áreas verdes no ambiente edificado, assumindo diversas funções, como melhoria das condições ambientais, estéticas e sociais à população - aspectos fundamentais para estabelecimento do conceito de cidade saudável.

Diversos estudos apontam os benefícios das áreas verdes no meio urbano devido à presença da vegetação, que pode melhorar a qualidade de vida da população urbana, uma vez que esse elemento promove a amenização do rigor térmico reduzindo a temperatura do ar, auxiliando na manutenção da umidade do ar e do solo, além de controlar a concentração de gás carbônico e de óxido de carbono durante o processo de evapotranspiração vegetal. A redução desses espaços pode levar a implicações negativas para os indivíduos, como o aumento de doenças de caráter respiratório (Pereira e Barbosa, 2019; Pereira e Barbosa, 2016; Barbosa, 2005).

Neste contexto, é importante salientar que as áreas verdes urbanas contribuem de forma significativa para o bem-estar social, mitigando os impactos negativos impostos pela dinâmica urbana frente ao processo de crescimento das cidades, ao permitir a manutenção do contato direto com a natureza. Assim, a vivência da cidadania dar-se, também, pelo crescente interesse por espaços verdes que promovam o lazer e a recreação (Cardoso et al., 2015) - elementos propulsores da saúde e da coesão social.

Neste cenário, o artigo buscou analisar os parques urbanos em duas capitais brasileiras localizadas nas regiões Norte e Nordeste do Brasil: Belém-PA e Recife-PE. Para tanto, foram analisados o padrão de distribuição e atendimento à população por meio da identificação, dimensões e estimativa de suas áreas de alcance. Pretendeu-se, a partir desta análise, estimar a parcela do território com acesso a serviços ecossistêmicos e, consequentemente, com maior potencial ao estabelecimento do conceito de Cidade Saudável (World Health Organization, 1946).

\section{Referencial teórico}

Em sua Constituição, de 1946, a Organização Mundial de Saúde - OMS (World Health Organization, 1946) define saúde com um "estado de completo bem-estar físico, social e mental" e defende a saúde como um "recurso para a vida cotidiana, não o objeto da vida", enfatizando, assim, os recursos sociais e pessoais, bem como as capacidades físicas.

A OMS (World Health Organization, s.d., a) alerta para a necessidade de equidade de acesso e de uma visão holística por parte dos governos locais no que toca as condições sociais e econômicas, ambiente físico, estilos de vida e saúde da população, uma vez que todos estão intimamente relacionados. Quanto às cidades, o órgão define como cidades saudáveis aquelas que estão "criando e melhorando continuamente os ambientes físicos e sociais e expandindo os recursos que permitem às pessoas apoiarem-se mutuamente no desempenho de todas as funções da vida e no desenvolvimento de seu potencial máximo".

De acordo com os dados da regional europeia da OMS (World Health Organization, s.d., b), o meio ambiente é um dos principais determinantes da saúde, sendo responsável por quase $20 \%$ de todas as mortes da Europa. Esta definição em conjunto com informações da regional europeia aponta 
para a necessidade de um contínuo monitoramento do ambiente urbano e adaptação, sempre que necessário, de políticas e estratégias de melhoria deste ambiente para atendimento das demandas da sociedade.

Os cinco aspectos mais relevantes, dentre os doze citados pelo organismo internacional, se conectam de forma mais direta com o objeto desta pesquisa, a saber: (a) qualidade do ar; (b) saúde urbana; (c) habitação; (d) mudanças climáticas e (e) ruído. Vale esclarecer, que no que tange a habitação, a instituição se refere não apenas à edificação que abriga a unidade familiar, mas também ao contexto urbano em que está inserida esta edificação e às relações que se estabelecem nesse ambiente.

Carneiro (1997) relata que os parques urbanos devem refletir o modo de viver da população, incluindo sua história, cultura e adaptação às características climáticas de cada localidade. Silva e Nogueira (2015) reforçam dizendo que estes espaços têm o objetivo de recriar a presença da natureza no meio urbano e contribui para minimizar os conflitos da vida citadina através de vários benefícios, como equilíbrio de temperatura e umidade, renovação do ar e aumento de áreas permeáveis, além do contato com a natureza.

Fundação CIDE (2004 apud Ferreira, 2005) amplia a lista dos benefícios ecossistêmicos das áreas verdes urbanas (Tabela 1) que podem amenizar ou combater os desdobramentos indesejados das intervenções antrópicas, relacionando-os com diferentes dimensões urbanas. Os benefícios listados pelos autores não apenas confirmam a relevância da existência de áreas verdes urbanas, mas também indicam a necessidade de um planejamento adequado para que os seus benefícios possam ser equitativamente usufruídos por toda a cidade.

\section{Tabela 1 - Benefícios das áreas verdes urbanas.}

Principais benefícios das áreas verdes urbanas

\begin{tabular}{|c|c|c|}
\hline \multicolumn{2}{|c|}{ Fatores urbanos } & Principais benefícios das áreas verdes \\
\hline \multirow{3}{*}{ Físico } & Clima e ar & $\begin{array}{l}\text { Conforto microclimático; controle da poluição } \\
\text { atmosférica; controle da poluição sonora }\end{array}$ \\
\hline & Água & $\begin{array}{c}\text { Regularização hídrica; controle da poluição } \\
\text { hídrica }\end{array}$ \\
\hline & Solo e subsolo & $\begin{array}{c}\text { Estabilidade do solo; controle da poluição } \\
\text { edáfica }\end{array}$ \\
\hline \multirow{2}{*}{ Biológicos } & Flora & Controle da redução da biodiversidade \\
\hline & Fauna & Controle de vetores \\
\hline \multirow{2}{*}{ Territorial } & Uso e ocupação do solo & $\begin{array}{l}\text { Conforto ambiental nas edificações; controle da } \\
\text { poluição visual }\end{array}$ \\
\hline & Infraestrutura e serviços & $\begin{array}{l}\text { Racionalização do transporte; saneamento } \\
\text { ambiental; conservação da energia }\end{array}$ \\
\hline Sociais & $\begin{array}{l}\text { Demografia, equipamentos } \\
\text { e serviços sociais }\end{array}$ & $\begin{array}{l}\text { Conscientização ambiental; atendimento das } \\
\text { necessidades sociais }\end{array}$ \\
\hline Econômicos & $\begin{array}{l}\text { Setores produtivos, renda e } \\
\text { ocupação }\end{array}$ & $\begin{array}{l}\text { Valorização das atividades e propriedades; } \\
\text { amenizações dos bolsões da pobreza }\end{array}$ \\
\hline Instituição & $\begin{array}{l}\text { Setor público; instrumentos } \\
\text { normativos }\end{array}$ & $\begin{array}{l}\text { Apoio à capacidade de gestão urbana; } \\
\text { instrumento de regulamentação específica }\end{array}$ \\
\hline
\end{tabular}

Fonte: Adaptado de Fundação CIDE (2004 apud Ferreira, 2005). 
Para Torres et al., (2013), a saúde e qualidade de vida devem ser assumidas como ponto fundamental em razão da atenção que deve ser dada aos momentos de tempo livre, lazer e à procura pelo equilíbrio psíquico e social, o que desperta a necessidade de materializar o conceito de "Cidades Saudáveis". Esse conceito tem como ponto de partida a requalificação urbana e valorização ambiental das cidades, através da criação de espaços pedonais e áreas verdes, entre outros; ou seja, requer um planejamento urbano saudável.

$\mathrm{Na}$ infraestrutura urbana, os parques assumem essa função, promovendo recreação, lazer e contato com a natureza, além de melhorar a qualidade do ar, amenizar temperaturas e fortalecer a cultura e as relações sociais entre seus usuários. Carneiro e Mesquita (2000) definem parques e praças da seguinte forma:

- Praças: são espaços livres públicos, com função de convívio social, inseridos na malha urbana como elemento organizador da circulação e de amenização pública, com área equivalente à da quadra, geralmente contendo expressiva cobertura vegetal, mobiliário lúdico, canteiros e bancos.

- Parques: são espaços livres públicos com função predominante de recreação, ocupando na malha urbana uma área em grau de equivalência superior à da quadra típica urbana, em geral apresentando componentes da paisagem natural - vegetação, topografia, elemento aquático - e edificações destinadas a atividades recreativas, culturais e/ou administrativas.

Para Meneses (2018), os parques podem ainda ser divididos em duas subcategorias:

- Parques de natureza: aqueles que têm como atração principal a flora, fauna ou outros elementos naturais, como cursos hídricos ou formações rochosas.

- Parques urbanos: espaços de uso público inseridos na malha urbana e que congregam elementos naturais e infraestrutura essencial à prática de lazer e de atividades esportivas [...].

Tendo em vista que, dentre as principais contribuições das áreas verdes para a saúde está a atratividade para a prática de atividades esportivas e a disponibilidade de equipamentos para tal, procedeu-se então uma pesquisa bibliográfica com o objetivo de identificar características, diretrizes ou recomendações desejáveis para os parques urbanos, equipamentos que podem proporcionar infraestrutura necessária a tais essas atividades. Em um estudo conjunto com a National Recreationand Park Association (NRPA) e com a American Academy for Park and Recreation Administration (AAPRA), Mertes e Hall (1995, p. 94) categorizam e listam recomendações para parques e espaços livres.

A tabela 2 apresenta de forma resumida as definições e recomendações propostas pelos autores. Apesar dos diferentes alcances propostos por Mertes e Hall (1995), mais recentemente, diante do reconhecimento científico dos benefícios das áreas verdes para a saúde e o bem-estar, autoridades, ativistas e pesquisadores têm defendido a necessidade de que todos os habitantes de uma cidade tenham acesso a uma área verde a até 10 minutos de caminhada de sua residência. $\mathrm{O}$ movimento é liderado nos Estados Unidos pelas instituições The Trust for Public Land (TPL), NRPA e Urban Land Institute (ULI) e tem como meta promover o acesso de todos os moradores de áreas urbanas do país a parques, em um percurso de até 10 minutos de caminhada, até 2050.

O percurso de 10 minutos, ou $800 \mathrm{~m}$, é defendido pela TPL como uma distância confortável a ser percorrida por todos os públicos e se baseia nas definições de $70 \%$ das maiores cidades americanas para a distância considerada "perto" (The Trust for Public Land, 2016).

É importante ressaltar que a distância e tempo indicados pela instituição norte-americana são corroborados no Brasil, pelo Departamento Nacional de Infraestrutura de Transportes (DNIT), que em seu Manual de projeto geométrico de travessias urbanas (Departamento Nacional de Infraestrutura de Transportes, 2010) cita como referência as definições da American Association of State Highway and Transportation Officials (AASHTO); ou seja, defende que a velocidade de deslocamento pedestre varia entre 0,8 e $1,8 \mathrm{~m} / \mathrm{s}$, o que equivale a uma velocidade entre 48 e 108 $\mathrm{m} / \mathrm{min}$. Em função dos diferentes públicos e necessidades, que englobam desde idosos e crianças à 
jovens em boas condições físicas, comumente se utiliza para estudos mais amplos a velocidade média de $78 \mathrm{~m} / \mathrm{min}$, o que equivale, de forma aproximada, a um percurso de $800 \mathrm{~m}$ em 10 minutos de caminhada.

Tabela 2 - Classificação e diretrizes para parques e espaços livres.

\begin{tabular}{|c|c|c|c|}
\hline \multicolumn{4}{|c|}{ Classificação e diretrizes para parques e espaços livres (NRPA) } \\
\hline Classificação & Descrição & Alcance & Dimensão \\
\hline Mini-parque & $\begin{array}{c}\text { Espaços dedicados a atender } \\
\text { necessidades limitadas ou } \\
\text { específicas de recreação }\end{array}$ & Até $400 \mathrm{~m}$ & 232 à $4.047 \mathrm{~m}^{2}$ \\
\hline $\begin{array}{l}\text { Parque de } \\
\text { vizinhança } \\
\text { (bairro) }\end{array}$ & $\begin{array}{c}\text { Unidade básica do sistema de } \\
\text { parques. Foco em atividades } \\
\text { de lazer para diversas faixas } \\
\text { etárias }\end{array}$ & $\begin{array}{c}\mathbf{4 0 0} \text { à } 800 \text { m } \\
\text { (percurso contínuo) }\end{array}$ & $\begin{array}{l}\text { Dimensão mínima: } \\
8.000 \text { m² (0.8 ha); } \\
\text { Dimensão ideal: } \\
\mathbf{2} \text { à 4ha }\end{array}$ \\
\hline $\begin{array}{l}\text { Parques } \\
\text { distritais }\end{array}$ & $\begin{array}{l}\text { Podem atender a diversas } \\
\text { vizinhanças ou bairros. Têm } \\
\text { atividades dia e noite e } \\
\text { facilidade de acesso por } \\
\text { diferentes modais }\end{array}$ & $\begin{array}{c}\mathbf{1 . 6 0 0} \text { à } \mathbf{4 . 8 0 0 ~} \mathbf{~ m} \\
(1.6 \text { e } 4.8 \mathrm{~km} \text { de } \\
\text { percurso })\end{array}$ & $\begin{array}{c}\text { Dimensão mínima: } \\
40.000 \text { m² (4 ha); } \\
\text { Dimensão ideal: } \\
6 \text { à 20ha }\end{array}$ \\
\hline $\begin{array}{c}\text { Grandes } \\
\text { parques urbanos }\end{array}$ & $\begin{array}{l}\text { Além das funções de lazer e } \\
\text { social podem também } \\
\text { atender a demandas de } \\
\text { conservação da natureza ou } \\
\text { da paisagem }\end{array}$ & $\begin{array}{l}\text { Geralmente atende a } \\
\text { toda a cidade ou } \\
\text { região (sem } \\
\text { delimitação de área } \\
\text { de alcance) }\end{array}$ & $\begin{array}{c}\text { Dimensão ideal: } \\
\text { Maior ou igual à } \mathbf{3 0} \\
\text { ha }\end{array}$ \\
\hline
\end{tabular}

Fonte: Adaptado de Mertes e Hall (1995, p. 94)

\section{Procedimentos metodológicos}

O presente artigo aborda a análise do padrão de distribuição e atendimento à população por parques urbanos em cidades brasileiras a partir do estudo de caso em duas capitais: Belém-PA e Recife-PE (Figura1).

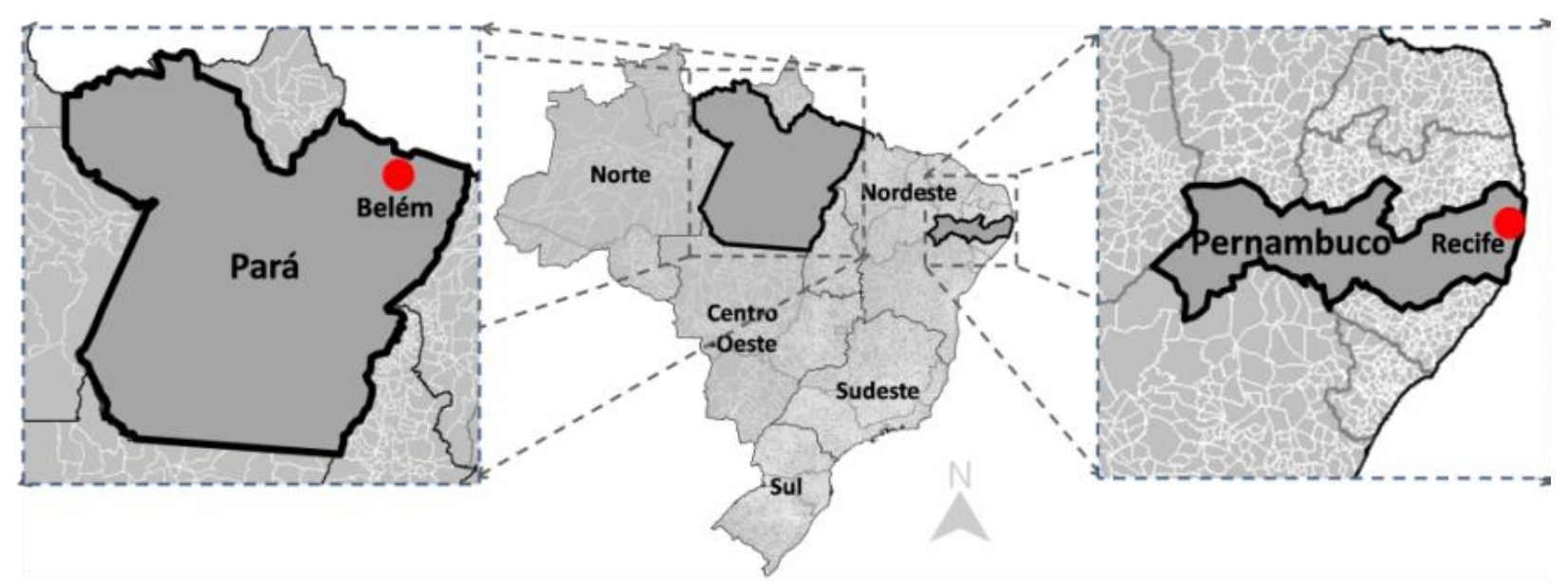

Figure 1 - Mapa de localização das cidades estudadas: Belém-PA e Recife-PE.

Fonte: Autores (2020)

Belém, capital do Pará, é uma cidade com cerca de 1,5 milhões de habitantes (Instituto Brasileiro de Geografia e Estatística, 2020 a), caracterizada por seu clima equatorial úmido, altas temperaturas e altos índices pluviométricos. Recife, capital de Pernambuco, está localizada no litoral 
nordestino, região com predominância do clima tropical atlântico que possui vasta área de mangue, florestas tropicais e resquícios de mata atlântica. Em relação à demografia da capital, atualmente, conta com 1,65 milhões de habitantes (Instituto Brasileiro de Geografia e Estatística, 2020 a).

A escolha das cidades se deu a fim de investigar a distribuição dos parques urbanos em capitais de diferentes regiões brasileiras e verificar aspectos como a quantidade de parques urbanos e a parcela do território coberta e atendida por estes equipamentos.

No intuito de avaliar o acesso equitativo da população aos possíveis benefícios proporcionados pelas áreas verdes nas duas capitais selecionadas, o primeiro passo foi definir os recortes dos equipamentos a serem estudados. Para tal, procedeu-se uma pesquisa bibliográfica sobre as áreas verdes de forma a definir quais delas proporcionam a maior quantidade de benefícios. $\mathrm{Na}$ etapa seguinte procedeu-se uma pesquisa documental com foco em dados sobre áreas verdes de acesso público. De acordo com os mapas e categorizações fornecidas pelos municípios, as áreas verdes estão distribuídas em três macro categorias: canteiros, praças e parques. Tendo em vista a grande diversidade de áreas verdes existentes nas cidades, procedeu-se uma pesquisa documental com o objetivo de identificar os parques urbanos de cada uma delas, assim como informações sobre localização e dimensão.

Os canteiros localizados ao longo do sistema viários, caracterizados por faixas de solo natural, muitas vezes vegetadas, apesar de não possuírem o mesmo potencial de benefícios das demais categorias, ainda têm a possibilidade de contribuir para a amenização climática e drenagem, mas por não contemplarem estrutura de suporte às funções de lazer, foram excluídos do recorte deste estudo. Quanto aos parques, que agregam múltiplas funções, foram espacializados nos mapas das cidades correspondentes, para que então se procedesse a definição do recorte e a delimitação das áreas de alcance. Considerando as definições apresentadas por Carneiro e Mesquita (2000), Meneses (2018) e Mertes e Hall (1995) e tendo por referência as indicações de que os benefícios das áreas verdes se dão também em função da prática de atividade esportivas nestas áreas, definiu-se como recorte de estudo os parques urbanos de vizinhança e distritais, ou seja, equipamentos com dimensões acima de 2 ha e que comportem, além de áreas verdes (função ecossistêmica e lazer passivo), infraestrutura para recreação e esportes (lazer ativo).

Ainda, com base nas referências da TPL e do DNIT relacionadas ao percurso, optou-se por definir como raio de alcance dos parques do recorte a medida de $800 \mathrm{~m}$, o equivalente a 10 minutos de caminhada. Nesta pesquisa, foram delimitadas manchas com raio de $800 \mathrm{~m}$ e centro localizado nos acessos de cada parque. Em parques com mais de um acesso, as respectivas manchas foram unidas em uma única peça, que definiu a área de alcance deste parque. Com o somatório destas áreas pretende-se estimar o percentual de área em cada cidade atendida pelos parques urbano integrantes do recorte. Com os resultados destes mapas e com dados coletados das cidades em estudo criou-se uma tabela que permite comparar a quantidade de parques, sua área e percentual de cobertura e alcance territorial. Desta forma será possível identificar qual das duas cidades estudadas proporciona a sua população o melhor acesso a parques urbanos e consequentemente gera maiores condições de saúde e bem-estar.

\section{Resultados}

\subsection{Parques Urbanos em Belém-PA}

A cidade de Belém integra em sua área urbana consolidada o total de cinco parques, sendo um municipal, três estaduais e um federal. Dos parques estudados, o Jardim Botânico Bosque Rodrigues Alves, com administração municipal, é o mais antigo e oferece atividades de recreação e lazer. O espaço foi criado, dentro da área urbana, em 1870, para preservação de uma parte da floresta Amazônica, e mantêm atualmente, nos seus 15ha, $80 \%$ de mata nativa preservada, com grande diversidade de fauna e flora pertencentes ao bioma Amazônico e ainda outras espécies exóticas plantadas no decorrer dos anos. Recebeu a classificação de Jardim Botânico, em 2002, quando iniciou produção científica com foco na conservação ambiental. Entre os diversos benefícios 
promovidos pelo parque, destacam-se a melhoria da qualidade ambiental do entorno, o controle climático e as atividades de lazer e educacionais (Lima \& Souza, 2019)(Figura 2a).

O Parque Zoobotânico Paraense Museu Emílio Goeldi, assim como o Bosque Rodrigues Alves, localiza-se em área central da cidade, e nos seus 5,2 ha estão distribuídos um conjunto arquitetônico composto por prédios históricos e diversos monumentos, além de espécies da fauna e flora regional, o que levou a ser tombado pelos Patrimônios Histórico e Artístico Nacional e Estadual. Abriga uma extensa área dedicada ao jardim zoológico, com viveiros de diferentes animais e plantas amazônicas. O local é aberto à visitação pública, mas agrega também produção científica, lazer contemplativo e educação ambiental (Figura 2b).

Inaugurado em 2005, o Parque Naturalista Mangal das Garças está localizado no entorno do Centro Histórico, ocupa uma área de4ha e contribuiu para revitalização de uma área de várzea, igapó e terra firme, na orla fluvial da cidade. O espaço possui espaços de exposição, restaurantes e lanchonetes, viveiros de plantas e animais da flora e fauna local, borboletário, lago e chafariz e um mirante de $47 \mathrm{~m}$ de altura, além de diversos pontos de estar e contemplação (Pereira \& Bahia, 2018). Contudo, o local necessita de manutenção frequente e, além disso, o projeto paisagístico não adotou o uso de espécies arbóreas com copas densas e perenes, o que acarreta em grande desconforto em alguns horários (Figura 2c).

O Parque Estadual do Utinga Camillo Vianna faz parte de uma Área de Proteção Ambiental Metropolitana de Belém (APA Belém). Nele localizam-se os mananciais de abastecimento de $60 \%$ da população da Região Metropolitana de Belém (RMB), numa extensa área remanescente de floresta (Henderson, 2014), com 1.393,04ha, classificada como Unidade de Conservação (UC), exerce papel fundamental na preservação da biodiversidade amazônica e no ecossistema local (Lima \& Souza, 2019). Está localizado em um bairro de padrão econômico classificado como médio baixo e baixo, e o que poderia ser um indicativo de inclusão e acesso de uma população menos favorecida à um espaço com bastante área verde, lazer e todos os benefícios ecossistêmicos provenientes de uma UC, não retrata a realidade. Pelo fato do parque apresentar apenas uma única entrada, restringe a possibilidade de uma parcela da população de acessá-lo à pé, em função de sua grande extensão. Contudo, outros pontos positivos podem ser destacados, como: entrada gratuita, visitas monitoradas e atividades de ecoturismo, além da infraestrutura para a prática de exercícios físicos e lazer (Figura $2 d)$.

O Parque Porto Futuro é o mais novo parque urbano. Inaugurado em agosto de 2020, está localizado em uma área portuária em processo de requalificação desde os anos 2000, com a criação de vários outros espaços, integrando um grande complexo turístico. O espaço foi doado ao Estado pelo governo federal, e por se tratar de área de marinha foi aproveitado como mais um espaço de lazer e entretenimento para a cidade, cuja administração está, atualmente, sob responsabilidade do município. Possui área de 2,38ha, com equipamentos para práticas esportivas, parque infantil, espaços de descanso e contemplação, lanchonetes e estacionamento. Apesar de apresentar diversificadas opções de lazer e entretenimento, está localizado em um bairro de padrão econômico de classe média alta a alta, e entorno próximo com uso predominantemente de comércio e serviço, o que desfavorece seu uso por uma grande parcela da população. Como pontos positivos, se destacam o fato de ter duas entradas, que permitem maior possibilidade de uso e facilita o acesso do público, independentemente de seu trajeto e, apesar de apresentar fechamento em gradil de ferro, possui entrada gratuita aos seus frequentadores. A obra foi entregue à população, porém corresponde a primeira fase do projeto, estando prevista mais uma etapa com novas atrações e espaços de entretenimento para uso público (figura $2 \mathrm{e}$ ).

\subsection{Parques Urbanos em Recife-PE}

De acordo com inventário produzido pelo Consórcio Projetec e Norconsult (Consórcio Projetec e Norconsult, 2016), Recife conta atualmente com quinze parques urbanos. Destes, seis parques foram excluídos da análise desta pesquisa: quatro por não se encaixarem no perfil de funções e estrutura que definem o recorte e dois por possuírem área abaixo da dimensão mínima definida. Aos selecionados, foram ainda adicionados o Parque do Jiquiá e o Parque Santos Dumont 
que, apesar de não terem sido incluídos no inventário acima citado, contemplam as funções ecossistêmicas e de lazer previstas na metodologia. Assim, ao todo, integram o recorte deste estudo na cidade do Recife, onze parques urbanos, dez deles sob a responsabilidade do governo municipal e um do governo estadual (Parque Santos Dumont).

Os parques da Macaxeira (Figura 3a), Caiara (Figura 3c), Santana (Figura 3d), Arnaldo Assunção (Figura 3f), Dona Lindu (Figura 3j) e Santos Dumont (Figura 3k) abrigam, em diferentes escalas, estrutura para lazer, esportes e cultura, além de áreas arborizadas. Destes é possível destacar a vocação esportiva dos Parques do Caiara e Santos Dumont que possuem quadras poliesportivas, pista para atletismo e campinhos de futebol, enquanto que o Dona Lindu se destaca pelo conjunto de teatro e galeria projetados pelo arquiteto Oscar Niemeyer. Todos são amplamente utilizados, no entanto os Parques do Caiara e Arnaldo Assunção são majoritariamente frequentados por moradores da vizinhança, enquanto os demais atraem visitantes de toda a cidade.

Quanto aos parques Sítio da Trindade/Arraial Velho do Bom Jesus (Figura 3b), da Jaqueira (Figura 3e), do Forte/Arraial Novo do Bom Jesus (Figura 3g) e 13 de Maio (Figura 3h), apesar de também abrigarem funções ecossistêmicas e de lazer, se caracterizam por seus valores históricos, o que garante a eles a inserção no conjunto de Zonas Especiais de Preservação Histórica (ZEPH) do Recife. Tanto o Sítio da Trindade como o Parque do Forte abrigam resquícios de fortes construídos durante as ocupações portuguesa e holandesa em Pernambuco. O Parque da Jaqueira, além de ser o mais visitado da cidade, é considerado também uma Unidade de Conservação da Paisagem (UCP) municipal e abriga uma capela histórica tombada pelo IPHAN.

O parque 13 de Maio foi primeiro parque histórico do Recife e integra o conjunto paisagístico do edifício da Faculdade de Direito (tombado pelo IPHAN). Está localizado na área central da cidade, o que lhe proporciona um fluxo muito grande de pessoas nos horários comerciais. Este parque possui também um mini zoológico e abriga importantes eventos comemorativos da cidade, a exemplo da tradicional celebração do dia das crianças, que conta com visitantes de toda a região metropolitana. (Almeida, Ramos, \& Jesus, 2017)

O Parque do Jiquiá (Figura 3i), recentemente transformado em Unidade de Conservação da Natureza (UCN), abriga, além de equipamentos de cultura e esportes, a única Torre de Atracação do Graff Zeppelin existente em todo o mundo, tombada a nível estadual (FUNDARPE) e em processo de tombamento pelo IPHAN. O parque é o maior da zona oeste, conta ainda com projeto para implantação de um conjunto de equipamentos científicos e culturais, cuja construção foi iniciada, mas logo interrompida, o que impacta de forma negativa nos serviços ofertados.

Quanto à localização na cidade, a disposição dos parques no mapa demonstra uma significativa concentração na região central, com alguns dos parques localizados ao longo do Rio Capibaribe (Figura 3c, 3d, 3e e 3h). Apenas dois parques estão localizados na zona sul (Figuras 3j e 3k) e um deles a Norte (Figura 3a). Identificou-se, ainda, que apenas um parque atende à população do centro, polo econômico e de comércio e serviços da cidade (Figura 3h). 


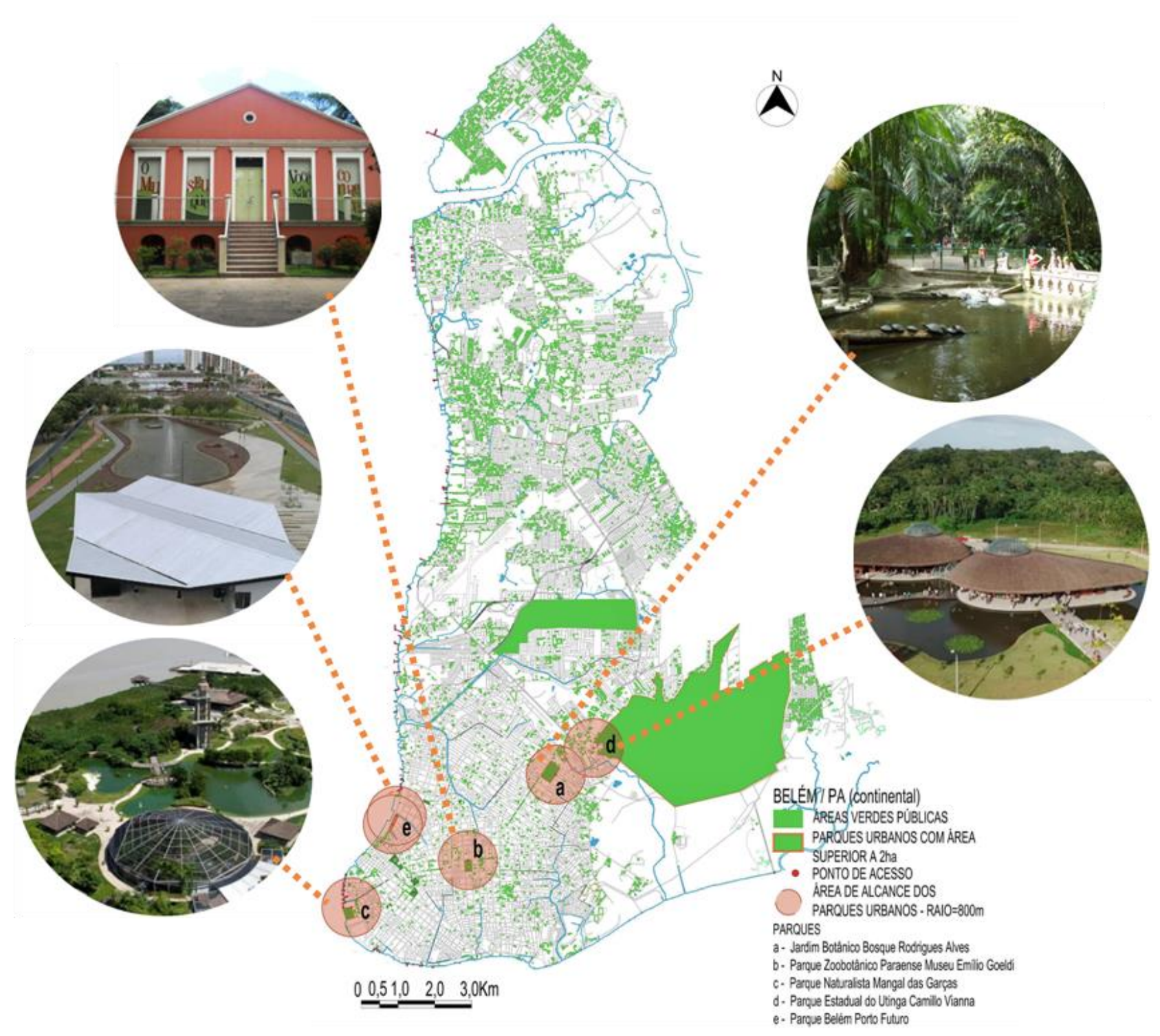

Figura 2: Mapa de Belém-PA com marcação dos parques e sua área de alcance integrantes do recorte.

Fonte: Autores (2020) 


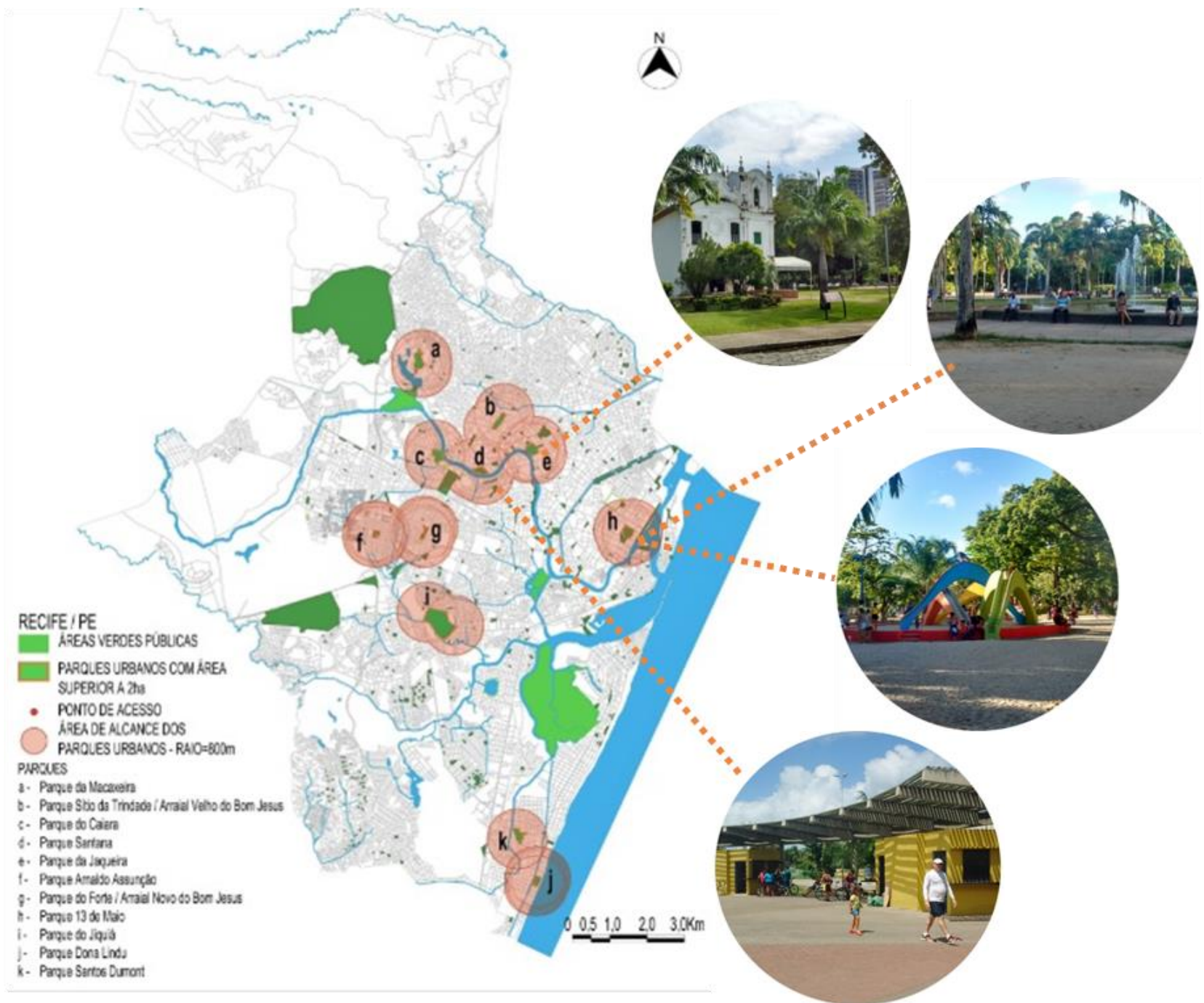

Figura 3: Mapa de Recife-PE com marcação dos parques e sua área de alcance integrantes do recorte.

Fonte: Autores (2020) 


\section{Discussões}

A porção continental de Belém conta com cinco parques urbanos, que estão dentro do recorte da pesquisa. Destes, um se configura como um parque ecológico que agrega também as funções de esporte e lazer. Os cinco parques estão localizados na região sul e sudoeste da cidade e, apesar da distribuição espaçada, contam com apenas um acesso na sua maioria, com exceção do Parque Porto Futuro que apresenta dois acessos.

O fato de possuir um único acesso é fator um limitador ao uso dos parques em Belém, uma vez que restringe suas áreas de alcance à população, pois o usuário pode precisar percorrer uma longa distância até o portão de acesso. Esta situação fica evidente quando se compara a área coberta por parques (1.419,62 ha) e a área de alcance da mesma cidade (954,51ha) (Tabela 1). Apesar de possuir uma grande área coberta por parques urbanos, a área atendida pelos mesmos é, praticamente, reduzida pela metade.

Este fenômeno se dá principalmente em função do Parque Estadual do Utinga Camillo Vianna (Figura 2d) que, apesar de sua grande extensão e da grande quantidade de equipamentos e atividades que oferece, o parque é cercado e possui apenas uma única entrada, o que dificulta o acesso da população à pé, em função de sua grande extensão.

Outra questão que deve ser considerada, para a cidade de Belém, se refere à localização dos parques. A maioria está próxima à bairros considerados de padrão alto ou médio alto e alguns não apresentarem o predomínio de uso residencial, como é o caso dos parques Jardim Botânico Bosque Rodrigues Alves, Parque Zoobotânico Paraense Museu Emílio Goeldi e Parque Porto Futuro (Figuras 2a, 2b e 2e), o que evidencia uma segregação e coloca a questão social em discussão, além de dificultar o acesso à pé aos referidos parques.

O mesmo não ocorre com os parques da cidade de Recife, os quais apresentam uma situação com melhor distribuição e maior quantidade de acessos. Assim, apesar de possuir menor área coberta por parques $(99,44$ ha), consegue atender a 2.497,15 ha, o que corresponde a $11,41 \%$ de seu território, enquanto os parques de Belém atendem apenas 5,40\% de sua área territorial.

Apesar de se destacar quanto ao número de acesso e a área de atendimento à população, em Recife, a concentração de parques em algumas áreas da cidade e contrapõe à total falta destes equipamentos em outras áreas. Dessa forma, enquanto algumas áreas são atendidas por até mais de um parque, outras estão bem distantes de qualquer um deles, privando boa parte da população da cidade de usufruir de seus benefícios.

Tabela 3: Atendimento dos parques em diferentes cidades. Fonte: Autores, 2020.

\begin{tabular}{|c|c|c|c|c|c|c|}
\hline \multicolumn{7}{|c|}{ Atendimento dos parques em diferentes cidades } \\
\hline $\begin{array}{c}\text { Cidade / } \\
\text { estado }\end{array}$ & $\begin{array}{c}\text { Área da } \\
\text { cidade (ha) }\end{array}$ & $\begin{array}{c}\text { Quantidade } \\
\text { de parques } \\
\text { (un) }\end{array}$ & $\begin{array}{c}\text { Área } \\
\text { coberta } \\
\text { por } \\
\text { parques } \\
\text { (ha) }\end{array}$ & $\begin{array}{c}\% \text { da } \\
\text { cidade } \\
\text { coberto } \\
\text { por } \\
\text { parques }\end{array}$ & $\begin{array}{c}\text { Área de } \\
\text { alcance } \\
\text { dos } \\
\text { parques } \\
\text { (ha) }\end{array}$ & $\begin{array}{c}\% \text { da } \\
\text { cidade } \\
\text { atendido } \\
\text { por } \\
\text { parques }\end{array}$ \\
\hline $\begin{array}{c}\text { Belém/PA } \\
\text { (continental) }\end{array}$ & $17.656,58$ & 5,00 & $1.419,62$ & $8,04 \%$ & 954,51 & $5,40 \%$ \\
\hline Recife/PE & $21.884,30$ & 11,00 & 99,44 & $0,45 \%$ & $2.497,15$ & $11,41 \%$ \\
\hline
\end{tabular}

Fonte: Autores (2020)

A falta de um planejamento urbano voltado para a conservação da natureza e para a saúde e bem-estar da população se reflete na pouca quantidade de parques e na ampla área da cidade sem atendimento pelos mesmos. Os dados apresentados na Tabela 1 demonstram que apenas $11,41 \%$ do 
território da cidade analisadas tem acesso conveniente e confortável aos benefícios ambientais e de saúde e bem-estar que os parques urbanos podem proporcionar. Em Recife, é preciso ainda considerar que a maior concentração de renda se dá na orla de Boa Viagem (a Sul) e na margem esquerda do Rio Capibaribe, região onde se localizam os parques 3a, 3b, 3d e 3e, da Figura 3.

Apesar do bairro de Boa Viagem ser contemplado com dois parques, ainda pode contar com toda a orla, que além dos banhos de mar, oferece infraestrutura para atividades de lazer e esportivas, como pistas para caminhada, ciclo faixa, parquinhos, quadras de tênis, rampa de skate, entre outros. A margem esquerda do rio conta com padrão similar de atenção pelo planejamento, visto que além dos parques integrantes do recorte, aguarda a implantação de um parque linear com um trecho em licitação $(1 \mathrm{Km})$ e trechos com projeto executivo já definido $(2 \mathrm{Km})$.

Quanto às demais áreas da cidade, principalmente a norte e a oeste, não contam com acesso conveniente a nenhum parque. É preciso ressaltar que estas áreas abrigam predominantemente a população de baixa renda, a qual tem ainda mais necessidade dos benefícios ecossistêmicos dos parques urbanos, visto que são os mais prejudicados pela geral insalubridade das áreas e edificações que ocupam, pelo grande adensamento e pelo risco de desastres aos quais estão continuamente submetidos.

\section{Considerações finais}

Os parques urbanos são fundamentais para as cidades, especialmente para promoção de lazer, diversão, contemplação da paisagem e saúde e bem-estar de seus usuários. Seus espaços arborizados e a presença de animais da fauna local garantem ao público frequentador contato direto com a natureza e com os diversos ecossistemas, a depender de cada localidade e clima. Esses benefícios acarretam em ganhos em termos de saúde física e mental da população, mas também representam ganho para a natureza, visto que estes espaços auxiliam na conservação da biodiversidade mesmo em meios urbanos.

A necessidade de não apenas conservar os existentes, mas também de implantar novos parques urbanos cresce a cada dia com as demandas emergentes das mudanças climáticas, que tendem a gerar ainda mais desconforto e riscos à infraestrutura das cidades e à saúde e bem-estar da população.

Os parques urbanos representam ainda grande oportunidade de educação patrimonial e ambiental. A promoção de atividades que fortaleçam a relação entre os cidadãos e estes espaços é também uma forma de ajudar na sua conservação e manutenção, além de contribuir para o aumento da vitalidade e, assim, coibir a insegurança muitas vezes percebida em alguns desses locais.

Para que estes objetivos sejam alcançados, no entanto, faz-se também imprescindível a implantação de programas educacionais e informativos para maior conscientização e conhecimento da população sobre a importância desses espaços para o seu próprio bem-estar e para a melhoria da qualidade de vida nas áreas urbanas. O estudo em questão encontrou dificuldade na etapa de coleta de dados, visto que as informações sobre os parques e as praças existente em cada cidade não são claras e a qualidade dos arquivos disponibilizados é, em certo ponto, precária, o que exigiu dedicação além do esperado para mineração dos dados necessários e preparação dos mapas.

Para as etapas posteriores, sugere-se que a área de atendimento seja delimitada a partir de análise morfológica, considerando o sistema viário existente e o percurso de $800 \mathrm{~m}$ a partir dos acessos aos parques.

Esta metodologia pode determinar com maior precisão o alcance de cada parque e até avaliar a oportunidade de abertura de novos acessos. Indica-se, ainda, fazer a sobreposição dos parques urbanos e de suas áreas de atendimento com mapas de renda de cada cidade, de forma a compreender a relação entre a distribuição destes equipamentos e a renda da população, ou seja, identificar possíveis desequilíbrios sociais. 


\section{Referencias}

Almeida, R., Ramos, L., \& Jesus, L. (2017). Estudos sobre os espaços livres de uso público e áreas verdes da regional 02. In Congreso de la Sociedad Ibero-americana de Gráfica Digital, XXI. Concepción.

Barbosa, R. V. R. (2005). Áreas verdes e qualidade térmica em ambientes urbanos: estudo em microclimas em Maceió (AL). 135 f. Dissertação de Mestrado, Universidade de São Paulo, São Carlos, Brasil.

Cardoso, S. L., Sobrinho, M. V., \& Vasconcellos, A. M. (2015). Gestão Ambiental de parques urbanos: o caso do parque ecológico do município de Belém Gunnar Vingren. (FapUNIFESP, Ed.) Urbe, Revista Brasileira de Gestão Urbana, 7 (1), 74-90.

Carneiro, A. R. (1997). O projeto e as funções e o uso dos parques urbanos do Recife. Paisagem e Ambiente, 167-187.

Carneiro, A. R., Mesquita, L. D. (2000). Espaços livres do Recife. Pernambuco. Brasil. Prefeitura da cidade do Recife / Universidade de Pernambuco.

Consórcio Projetec e Norconsult. (2016). Espaços públicos. Levantamento e cadastro dos parques, praças e áreas verdes da cidade do Recife. Vol I a VI., EMLURB - Empresa de manutenção e limpeza urbana, Recife.

Departamento Nacional de Infraestrutura de Transportes. (2010). Manual do projeto geométrico de travessias urbanas. Departamento Nacional de Infraestrutura de Transportes, Instituto de Pesquisas Rodoviárias, Rio de Janeiro. Acesso em 04 de Novembro de 2020, disponível em https://www.gov.br/dnit/pt-br/assuntos/planejamento-e-pesquisa/ipr/coletanea-demanuais/vigentes/740_manual_projetos_geometricos_travessias_urbanas.pdf

Ferreira, A. D. (2005). Efeitos positivos gerados pelos parques urbanos: o caso do Passeio Público da Cidade do Rio de Janeiro, 99. Niteroi, Rio de Janeiro: Dissertação (Mestrado em Ciência Ambiental) - Universidade Federal Fluminense.

Henderson, B. L. (2014). Valoração Ambiental do Parque Estadual do Utinga na Região Metropolotana de Belém-PA. Enciclopédia Biosfera, 10(18), 3460-3469.

Instituto Brasileiro de Geografia e Estatística. (2020 a). Belém. (Instituto Brasileiro de Geografia e Estatística - IBGE) Acesso em 05 de Dezembro de 2020, disponível em IBGE Cidades: https://cidades.ibge.gov.br/brasil/pa/belem/panoramaHenderson, B. L. (2014). Valoração Ambiental do Parque Estadual do Utinga na Região Metropolitana de Belém-Pa. Enciclopédia Biosfera, 10 (18), 3460-3469.

Instituto Brasileiro de Geografia e Estatística. (2020 b). Recife. (Instituto Brasileiro de Geografia e Estatística - IBGE) Acesso em 05 de Dezembro de 2020, disponível em IBGE Cidades: https://cidades.ibge.gov.br/brasil/pe/recife/panorama

Lima, J. S., Souza, F. T. (2019). Parques urbanos em Belém do Pará, do Urbanismo embelezador à preservação ambiental. XVIII ENANPUR (pp. 1-28). Natal: UFRN.

Meneses, A. R. (2018). Desafios da gestão dos parques urbanos de Recife. Dissertação de Mestrado, UFPE, Programa de Pós-Graduação em Desenvolvimento Urbano, Recife.

Mertes, J. D., \& Hall, J. R. (1995). Park, recreation, open space and greenway guidelines. Urban Land Institute.

Pereira, J. D. S.; Barbosa, R. V. R. (2016). Análise das áreas verdes urbanas e sua influência na redução do rigor térmico em cidade de clima semiárido. $12 \mathrm{p}$. Anais do $7^{\circ}$ Congresso Luso Brasileiros para o Planejamento Urbano, Regional, Integrado e Sustentável - PLURIS 2016. Maceió-AL.

Pereira, J. D. S.; Barbosa, R. V. R. (2019). Diagnóstico da influência de áreas verdes urbanas na redução do rigor térmico em cidade de clima semiárido. 23p. Anais do XVIII Encontro Nacional da Associação Nacional de Pós-Graduação e Pesquisa em Planejamento Urbano e Regional - ENANPUR 2019. Natal-RN.

Pereira, P. V., Bahia, M. C. (2018). O olhar dos usuários de lazer sobre o parque Mangal das Garças em Belém/PA. Rbel - Revista Brasileira de Estudos do Lazer, 5 (1), 95-108. 
Silva, J., Nogueira, H. (2015). Contributo dos espaços verdes para o bem estar das populações estudo de caso em Vila real. Cadernos de Geografia, 33, 117-121.

The Trust for Public Land. (25 de Fevereiro de 2016). Parks on the clock: why we believe in the 10minute walk. Acesso em 4 de Novembro de 2020, disponível em The Trust for Public Land: https://www.tpl.org/blog/why-the-10-minute-walk

Torres, M., Silva, L. T., Santos, L., Mendes, J. F. (2013). Saúde e bem-estar em meio urbano: das políticas à prática. Revista Portuguesa de Saúde Pública, 31 (1), 95-107.

World Health Organization. (1946). Constitution. Acesso em 07 de novembro de 2020, disponível em World Health Organization: https://www.who.int/about/who-we-are/constitution

World Health Organization. (s.d., a). Environment and health. (World Health Organization). Acesso em 10 de Dezembro de 2020, disponível em World Health Organization - Regional Office for Europe: https://www.euro.who.int/en/health-topics/environment-and-health

World Health Organization. (s.d., b). What is a healthy city? (World Health Organization). Acesso em 10 de Dezembro de 2020, disponível em World Health Organization - Regional Office for Europe: $\quad$ https://www.euro.who.int/en/health-topics/environment-and-health/urbanhealth/who-european-healthy-cities-network/what-is-a-healthy-city. 